\title{
Colour Vision Abnormalities in Multiple Sclerosis
}

\author{
Alexandra C. Harrison, Werner J. Becker and William K. Stell
}

\begin{abstract}
A battery of colour vision tests was employed to evaluate visual function in patients with multiple sclerosis (M.S.). Colour deficits were found in $45 \%$ of patients tested with the Ishihara plates and $42.5 \%$ of patients tested with the FM 100-Hue test. $65 \%$ of M.S. patients failed at least one of the tests.

The colour vision deficits were not restricted to patients with optic neuritis or with visual evoked potential (VEP) abnormalities and there was no significant correlation between an abnormal VEP latency and a colour vision deficit. Colour vision testing may be a useful option to consider in the investigation of M.S. patients, even if there is no other evidence of visual system involvement.
\end{abstract}

RÉSUMÉ: Anomalies de la vision des couleurs dans la sclérose en plaques Une batterie de tests de vision des couleurs a servi à évaluer la fonction visuelle de patients atteints de sclérose en plaques. Des déficits de vision des couleurs ont été détectés chez $45 \%$ des patients évalués à l'aide des plaques d'Ishihara et chez $42 \%$ des patients évalués à l'aide du test des nuances FM-100. Soixante-cinq pour cent des patients atteints de sclérose en plaques ont échoué à au moins un des deux tests.

Les déficits de vision des couleurs ne se limitaient pas aux patients souffrant de névrite optique ou d'anomalies des potentiels évoqués visuels (VEP) et aucune corrélation n'a été relevée entre une latence de VEP anormale et le déficit de vision des couleurs. Les tests de vision des couleurs pourraient se révéler une option utile dans l'investigation des malades atteints de sclérose en plaques, même s'il n'y a aucune autre manifestation au niveau du système visuel.

Can. J. Neurol. Sci. 1987; 14:279-285

The diagnosis of multiple sclerosis is dependent upon objective evidence of lesions in anatomically distinct parts of the central nervous system. Although autopsy studies indicate a predilection for plaques of demyelination in the visual system, ${ }^{1}$ disturbances of visual function may not be detectable with the Snellen visual acuity chart. Tests which can objectively document visual symptoms or demonstrate subclinical visual impairment may be valuable in establishing the diagnosis and evaluating the progress of the disease.

In the past few years a number of sensitive visual tests, both electrophysiological and psychophysical, have been employed in the investigation of patients with M.S. The electrophysiological test most often employed is the visual evoked potential (VEP). A delayed response to a transient pattern-reversal VEP is regarded by some authors as "the most reliable index of optic nerve pathology" 2 and "promises to provide the best test available of the presence of optic nerve plaques". 3 Psychophysical techniques, which require a conscious response from the subject, may utilize a variety of specific temporal or spatial stimuli. ${ }^{4}$
Results with VEP and psychophysical testing may be correlated in some instances ${ }^{5}$ but not in others. ${ }^{6}$ This does not indicate that one test is necessarily 'best' but rather that complementary information may be obtained by a battery of tests.

Previous studies have analyzed colour vision and VEP's in patients with retrobulbar neuritis, ${ }^{7}$ in the recovery period following acute papillitis, ${ }^{8}$ and with clearly documented previous optic neuritis. ${ }^{9}$ In the present study, we did not restrict our investigation to only those patients who had already been diagnosed as having optic neuritis since it is often difficult to make a retrospective diagnosis of retrobulbar neuritis. This may contribute to the variability one finds in defining the relationship between optic neuritis and multiple sclerosis. ${ }^{9}$ In addition, we did not assume that patients with a prior history of retrobulbar neuritis could be a control population to validate the colour vision testing in M.S. ${ }^{10}$ because we queried whether the visual deficits might occur in anatomical sites other than the optic nerve. Theories and data regarding higher-order neurons which process information from the 'long', 'middle', and 'short' wave-

From The Lions Sight Center. Faculty of Medicine. University of Calgary and The Calgary General Hospital

Received August 15, 1986. Accepted in final form March 29. 1987.

Reprint requests to: Alexandra Harrison. Canadian Medical Association, 1867 Alta Vista Drive, Ottawa, Ontario K1G 0G8 Canada 
length sensitive cones suggest that an enormously complex mechanism, which may well be post-chiasmal, is involved in the analysis of chromatic information. "

This research was conducted to determine whether standard clinical tests of colour vision might be useful in evaluating visual function in patients with multiple sclerosis and which colour vision tests are most appropriate for testing M.S. patients. If colour vision is disturbed, we questioned which spectral regions are affected and whether the findings with colour vision testing, a psychophysical measure, correlate with other indices of visual function, particularly the VEP which is an electrophysiological test.

\section{Materials ANd Methods}

\section{Subjects}

Forty patients with M.S. were investigated. Three groups of patients were identified on the basis of the VEP results: Group 1 - VEP normal in one eye, delayed in the other eye ( $N$ $=14$ patients)

Group 2 - VEP delayed in both eyes ( $N=19$ patients)

Group 3 - VEP normal in both eyes ( $N=7$ patients)

A group of 27 control subjects matched to the patient group by age and sex, was also evaluated.

\section{Evaluation Procedure}

All patients were evaluated neurologically and also by the following visual tests: visual acuity - at $1 / 3$ meter and six meters, visual evoked potentials following monocular and binocular stimulation, a fundus examination, static visual fields on the Friedman analyzer, a binocular vision investigation, and a colour vision evaluation. All of these tests were completed on the same day.

A history of optic neuritis was assumed if either: (a) there was a history of visual signs or symptoms including reduced (corrected) visual acuity or visual field deficits, or (b) there was optic atrophy (as evidenced by abnormally pale optic discs) at the time of this examination. Patients meeting either of these criteria will be referred to as "having (or having had) optic neuritis", although none of them were in an acute phase when examined and tested.

Following the neurological examination, patients were classified by the criteria of McDonald and Halliday ${ }^{12}$ and their disability evaluated on a scale from $\mathrm{K} 0$ to $\mathrm{K} 10$ suggested by Kurtzke. ${ }^{13}$ Patients were not diagnosed on the basis of the cerebrospinal fluid findings (increased proportion of IgG or oligoclonal bands) or the evoked potential findings. However, results on these two tests confirmed the clinical diagnosis and would have resulted in a more "definite" classification in a number of patients.

Visual evoked potentials were elicited with a pattern reversal display and averaged with a Nicolet CA 1000 signal averager. The stimulus was a high-contrast 27.5 minute check pattern reversing at $1.88 \mathrm{~Hz}$. Potentials were recorded from $\mathrm{Oz}$ to $\mathrm{Cz}$ electrodes with the ear as ground. VEP's were considered abnormal if the latency of the first major positive peak (PI00 or P1) exceeded 116 milliseconds ( $\mathrm{msec}$ ), or if the interocular difference was greater than $6 \mathrm{msec}$ (both criteria exceeded our normal mean by three standard deviations).

\section{Colour Vision Testing}

Monocular colour vision was screened with the City University Plates, the American Optical-Hardy Rand Rittler Plates (AO-HRR), the Ishihara Plates (the first 25 plates of the 38 -plate series in the 1981 edition), and the Farnsworth Dichotomous Test (Panel D-15). The Farnsworth-Munsell 100-Hue Test (FM 100-Hue) was used to provide a more in-depth assessment of colour vision performance. Illumination for colour vision testing was one Verilux Daylight Bulb with a correlated colour temperature of $6,200^{\circ} \mathrm{K}$ and a colour-rendering index of 93 , giving an illuminance of $645 \mathrm{Lux}$. Testing was done against a neutral grey flannel backdrop and table cover; test plates were positioned on a MacBeth Daylight Lamp stand to maintain a constant angle to the light source and the subject; the testing distance was one meter. All tests were used, unaltered, as received from the manufacturer, and except for the FarnsworthMunsell tests, were administered according to the instructions provided by the manufacturer. The Farnsworth-Munsell is a full spectrum arrangement test which assesses hue discrimination. The test consists of 85 "caps" containing different coloured discs which are equally distributed in 4 rectangular "boxes", each of which covers $1 / 4$ of the full spectrum. The subject is required to arrange the caps in each box in a regular colour sequence between the coloured reference caps which are attached at each end of each box. The test is scored by checking the numbers on the underside of the caps. If the numbers do not run consecutively, an error score can be calculated and plotted on a polar diagram.

The Farnsworth-Munsell tests were administered according to the manufacturer's instructions, with two exceptions: (a) time allowed for each box was not restricted; and (b) the coloured caps with the Panel D-15 and FM 100-Hue were displayed for subject selection in random order on the neutral grey table cover to facilitate handling, since some of our patients had difficulty with fine motor control. In cases of severe disability, the patient would point to the cap he wished to select and the examiner would place it in the wooden case.

\section{RESULTS}

\section{Screening Tests}

City University Test - In the patient group, errors were made in only 2 of 80 eyes tested (2.5\%). In the control group, no errors were made.

Panel D-15 Test - In the patient group, errors were made viewing with 12 of 80 eyes (15\%). In the control group, errors were made viewing with 6 of 54 eyes (11.1\%). No pattern was evident in the occurrence of errors in either the control group or the patient group.

AO-HRR Plates - In the patient group, errors were made viewing with 26 of 80 eyes (32.5\%) in 20 of 40 patients. Plate Number 3 was missed by all those who made errors and was the only misjudged plate in approximately half of the patients in which the errors occurred (i.e., 12/26 eyes). In the control group Plate Number 3 was missed by only one subject, using either eye, giving an error frequency of 2 of 54 eyes or $3.7 \%$.

Ishihara Plates (see Table 1) - In this study the most satisfactory Pass/Fail criterion was one error in the first 16 plates (i.e., 
two or more errors were considered a failure). By this stundard, approximately 30 percent of M.S. eyes ( $45 \%$ of patients) were abnormal and approximately 11 percent of control eyes (or subjects) were abnormal.

\section{Farnsworth-Munsell 100-Hue Test}

\section{a) Norms}

Because of indications that hue discrimination decreases with age,${ }^{14}$ we did not assume that a total error score of 100 or greater indicated "low discrimination" as suggested by the FM 100-Hue Test Manual. ${ }^{15}$ Rather, we used Verriest's age-related guidelines. ${ }^{16}$ Our control population data were used to validate our testing methods and to confirm the suitability of Verriest's norms for this study. Our controls show lower scores than Verriest's subjects in most age categories (see table 2). By using Verriest's norms (maximum observed in $95 \%$ of his population) rather than our own control data, we adopted a conservative approach for assessing patient failure; in addition, widespread use of the Verriest standard facilitates comparison of results.

\section{B) Quantitative Assessment of Abnormalities}

Percentages Abnormal performance on the FM 100-Hue test was approximately five times more frequent in the M.S. patient group than in our control group. Using Verriest's criterion, $28 / 80$ eyes $(35 \%)$ in $17 / 40$ patients $(42.5 \%)$ were abnormal, whereas $4 / 56$ eyes in $2 / 28$ control subjects $(7 \%)$ were abnormal.

Means (See Table 3) In six of seven age categories, the mean error scores for all M.S. patients were considerably higher than the means for Verriest's or our own control subjects. In principle, the elevation of means in M.S. could be due, either to an elevation of individual error scores to varying degrees in all

\begin{tabular}{|c|c|c|c|c|c|}
\hline \multirow{2}{*}{$\begin{array}{c}\begin{array}{c}\text { Plate } \\
\text { Number }\end{array} \\
\end{array}$} & \multicolumn{2}{|c|}{ Number of Errors (Eyes) } & \multirow{2}{*}{$\begin{array}{c}\text { Correct } \\
\text { Response }\end{array}$} & \multicolumn{2}{|c|}{ Most Common Error } \\
\hline & Controls/54 & Patients/80 & & Controls & Patients \\
\hline 1 & \multicolumn{2}{|c|}{ DEMONSTRATION PLATE } & 12 & \multirow[b]{2}{*}{ - } & \multirow[b]{2}{*}{ - } \\
\hline 2 & - & - & \multirow{2}{*}{$\begin{array}{l}8 \\
6\end{array}$} & & \\
\hline 3 & - & - & & - & \multirow{2}{*}{$\overline{20}$} \\
\hline 4 & $2(3.7 \%)$ & $5(6.3 \%)$ & 29 & 20 & \\
\hline 5 & - & $4(5.0 \%)$ & 57 & \multirow{2}{*}{$\overline{-}$} & $\begin{array}{l}20 \\
67\end{array}$ \\
\hline 6 & - & - & 5 & & - \\
\hline 7 & $11(20.4 \%)$ & $13(16.3 \%)$ & 3 & 8 & 8 \\
\hline 8 & - & $2(2.5 \%)$ & 15 & - & \multirow{2}{*}{71} \\
\hline 9 & $8(14.8 \%)$ & $18(22.5 \%)$ & 74 & 71 & \\
\hline 10 & $1(1.9 \%)$ & $1(1.3 \%)$ & 2 & 8 & 8 \\
\hline 11 & - & $5 \quad(6.3 \%)$ & 6 & - & 8 \\
\hline 12 & $12(22.2 \%)$ & $38(47.5 \%)$ & 97 & 87 & 87 \\
\hline 13 & $5(9.3 \%)$ & $6(7.5 \%)$ & 45 & 46 & * \\
\hline 14 & - & - & 5 & - & - \\
\hline 15 & - & - & 7 & - & - \\
\hline 16 & - & - & 16 & - & - \\
\hline 17 & $15(27.8 \%)$ & $30(37.5 \%)$ & 73 & $78 ; 23$ & $78 ; 23$ \\
\hline 18 & $8(14.8 \%)$ & $18(22.5 \%)$ & No & * & 5 \\
\hline 19 & $13(24.1 \%)$ & $18(22.5 \%)$ & Number & 2 & $2 ; 8$ \\
\hline 20 & $26(48.1 \%)$ & $45(56.3 \%)$ & Pattern & 45 & * \\
\hline 21 & $15(27.8 \%)$ & $20(25.0 \%)$ & Only & $*$ & * \\
\hline & & TAN DEUT & C" PLATE & & \\
\hline 22 & $1(1.9 \%)$ & $5(6.3 \%)$ & 26 & 28 & 28 \\
\hline 23 & - & $5 \quad(6.3 \%)$ & 42 & - & 4 \\
\hline 24 & - & $4(5.0 \%)$ & 35 & - & 3 \\
\hline 25 & $1 \quad(1.9 \%)$ & $3(3.8 \%)$ & 96 & 86 & 9 \\
\hline
\end{tabular}

* No consistent error.

- No error made.

\begin{tabular}{lcccrc}
\hline \multicolumn{3}{l}{ Table 2: Farnsworth-Munsell 100-Hue Test: Norms } \\
\hline \hline & \multicolumn{7}{c}{ Verriest } & \multicolumn{2}{c}{ Controls } \\
\cline { 2 - 6 } Age & N (Subjects) & Observed & $\begin{array}{c}\text { 2 S.D. } \\
\text { Above-Mean }\end{array}$ & N (Eyes) & $\begin{array}{r}\text { 2 S.D. } \\
\text { Above Mean }\end{array}$ \\
\hline $20-24$ & 94 & 74 & 98.7 & 8 & 64.9 \\
$25-29$ & 51 & 92 & 106.2 & 8 & 167.2 \\
$30-34$ & 33 & 106 & 125.1 & 14 & 116.0 \\
$35-39$ & 37 & 120 & 125.2 & 6 & 51.3 \\
$40-44$ & 32 & 134 & 119.4 & 4 & 278.1 \\
$45-49$ & 30 & 144 & 169.0 & 4 & 103.8 \\
$50-54$ & 38 & 154 & 134.1 & 2 & 80.5 \\
$55-56$ & 31 & 164 & 180.5 & & 108.0 \\
\hline
\end{tabular}

Observed $=$ Maximum Score Observed in 95\% of Population. 
patients, or to an increase in the number of patients having an elevated error score. Therefore, we further subdivided the patient data into two groups, one representing eyes with "normal" error scores and one representing eyes with "abnormally high" error scores. The means for the "normal" group were in fact equivalent to the means for both Verriest's and our own control groups, whereas the means for the "abnormally high" group were about 2-3 times as large as the means for controls. The increase in mean error scores of M.S. patients, therefore, reflects the fact that some patients have much higher error scores than normal, whereas others perform within normal limits on the FM 100-Hue test. This suggests that the discrimination ability in the M.S. patients was normal and that the abnormally high error scores were due to disturbances in colour vision function, not just diminished discrimination ability.

\section{C) Spectral Location of Abnormalities}

Circular Graphs A circular graph of error scores may be constructed on the score sheet diagram to determine in which area of the spectrum errors occur. Visual inspection of the 28 charts of eyes with abnormal error scores revealed a generalized decrease in discrimination in most subjects. The majority of defects (18) involved "blue" losses.

Linear Graphs To further investigate which area of the spectrum was affected, mean partial scores were plotted for the 10 caps representing hues identified on the FM 100-Hue circular diagram (see Figure 1). The data were plotted in five-year age categories for five groups of subjects including: three patient groups - (a) those with normal FM 100-Hue scores, (b) those with abnormal FM 100-Hue scores, and (c) the total group of patients in each category; and two control groups: (d) Verriest's and (e) our own.

The information was analyzed in greater detail for the two largest groups of patients with abnormal error scores, ages 25 to 29 and 35 to 39. Mean partial scores for all 85 caps for these groups were plotted against Verriest's norms for the same groups (Figure 2).

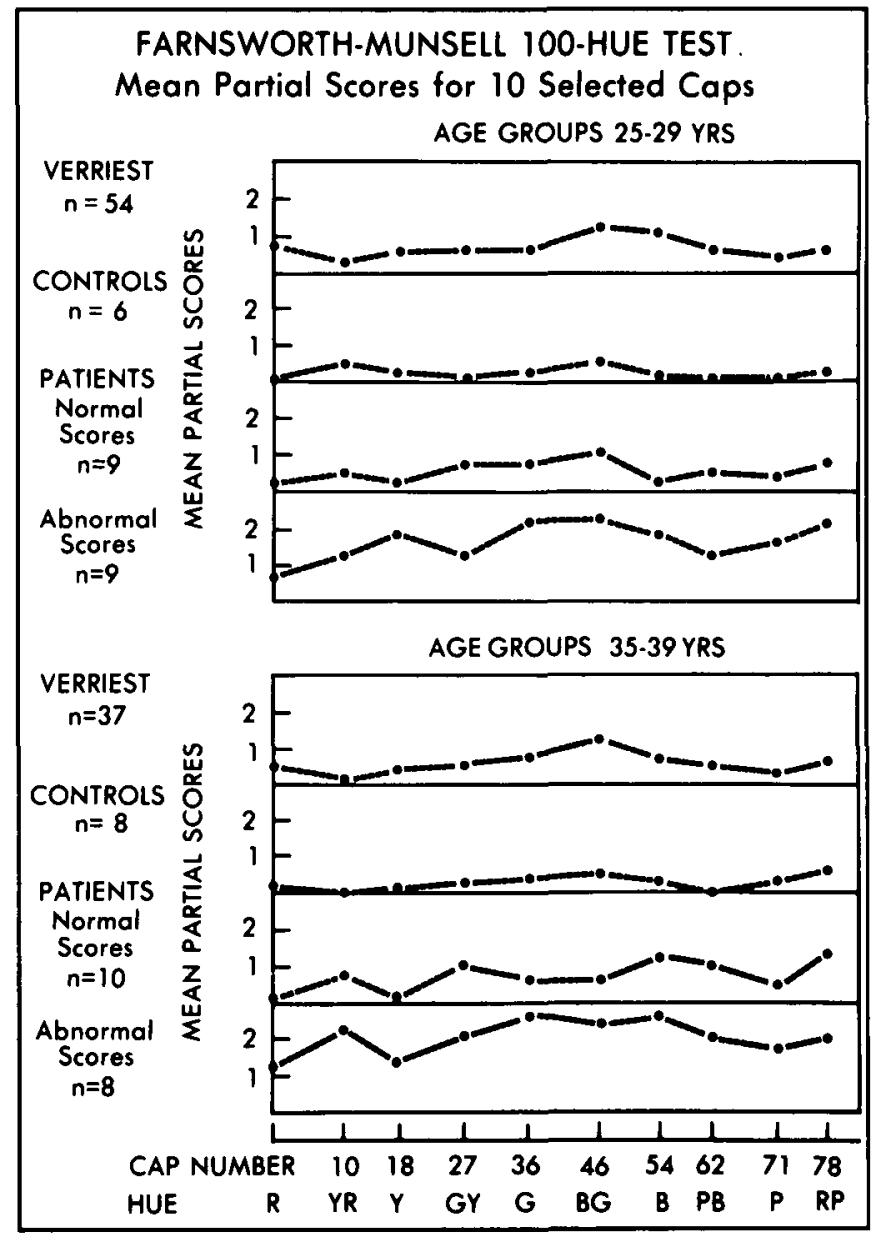

Figure l - M.S.patients withnormalFM-100Hue scores demonstrate colour discrimination which is similar to the Verriest control population. M.S. patients with abnormal error scores on the FM-100 Hue test demonstrate a generalized loss in wavelength discrimination which is most pronounced in the blue to green area of the spectrum.

Table 3: Farnsworth-Munsell 100-Hue Test: Mean Total Error Scores

\begin{tabular}{|c|c|c|c|c|}
\hline $\begin{array}{c}\text { Age } \\
\text { Category }\end{array}$ & $\begin{array}{c}\text { Norms } \\
\text { (Verriest) }\end{array}$ & $\begin{array}{c}\text { M.S. Patients with } \\
\begin{array}{c}\text { Normal Scores } \\
\text { (N Eyes) }\end{array}\end{array}$ & $\begin{array}{c}\text { M.S. Patients with } \\
\text { Abnormal Scores } \\
\text { (N Eyes) }\end{array}$ & $\begin{array}{l}\text { All M.S. } \\
\text { Patients } \\
\text { (N Eyes) }\end{array}$ \\
\hline $20-24$ & 36.3 & $\begin{array}{r}56.0 \\
(7)\end{array}$ & $\begin{array}{c}210.0 \\
\text { (3) }\end{array}$ & $\begin{array}{c}114.0 \\
(10)\end{array}$ \\
\hline $25-29$ & 47.4 & $\begin{array}{r}50.5 \\
(9)\end{array}$ & $\begin{array}{c}139.1 \\
\text { (9) }\end{array}$ & $\begin{array}{l}94.8 \\
(18)\end{array}$ \\
\hline $30-34$ & 54.7 & $\begin{array}{l}47.0 \\
(13)\end{array}$ & $\begin{array}{c}127.7 \\
(5)\end{array}$ & $\begin{array}{l}70.9 \\
(18)\end{array}$ \\
\hline $35-39$ & 56.8 & $\begin{array}{l}58.9 \\
(10)\end{array}$ & $\begin{array}{c}161.3 \\
(8)\end{array}$ & $\begin{array}{c}104.4 \\
(18)\end{array}$ \\
\hline $40-44$ & 62.4 & $\begin{array}{r}89.8 \\
(4)\end{array}$ & $\begin{array}{c}181.0 \\
(2)\end{array}$ & $\begin{array}{c}120.2 \\
(6)\end{array}$ \\
\hline $45-49$ & 90.4 & $\begin{array}{r}89.5 \\
(4)\end{array}$ & $\overline{(0)}$ & $\begin{array}{c}89.5 \\
(4)\end{array}$ \\
\hline $50-54$ & 71.5 & $\begin{array}{r}66.6 \\
(5) \\
\end{array}$ & $\begin{array}{c}163.0 \\
\text { (1) }\end{array}$ & $\begin{array}{c}82.7 \\
(6)\end{array}$ \\
\hline TOTAL N (Eyes) & & $(52)$ & $(28)$ & (80) \\
\hline
\end{tabular}

Mean scores for M.S. patients' eyes with 'normal' FM 100-Hue total error scores were similar to mean scores for Verriest's norms. (Mean scores for M.S. Patients with abnormal total error scores, and mean scores for all M.S. patients in each category are much higher than those of norms.) 
With both these methods of analyzing the data, M.S. patients with abnormal error scores demonstrated generally higher mean partial scores, indicating a generalized reduction in wavelength discrimination which was most pronounced in the blue to green areas of the spectrum.

Noticeable minima occur in these score-vs-cap (hue) functions near the location of the reference caps. To examine the "Box

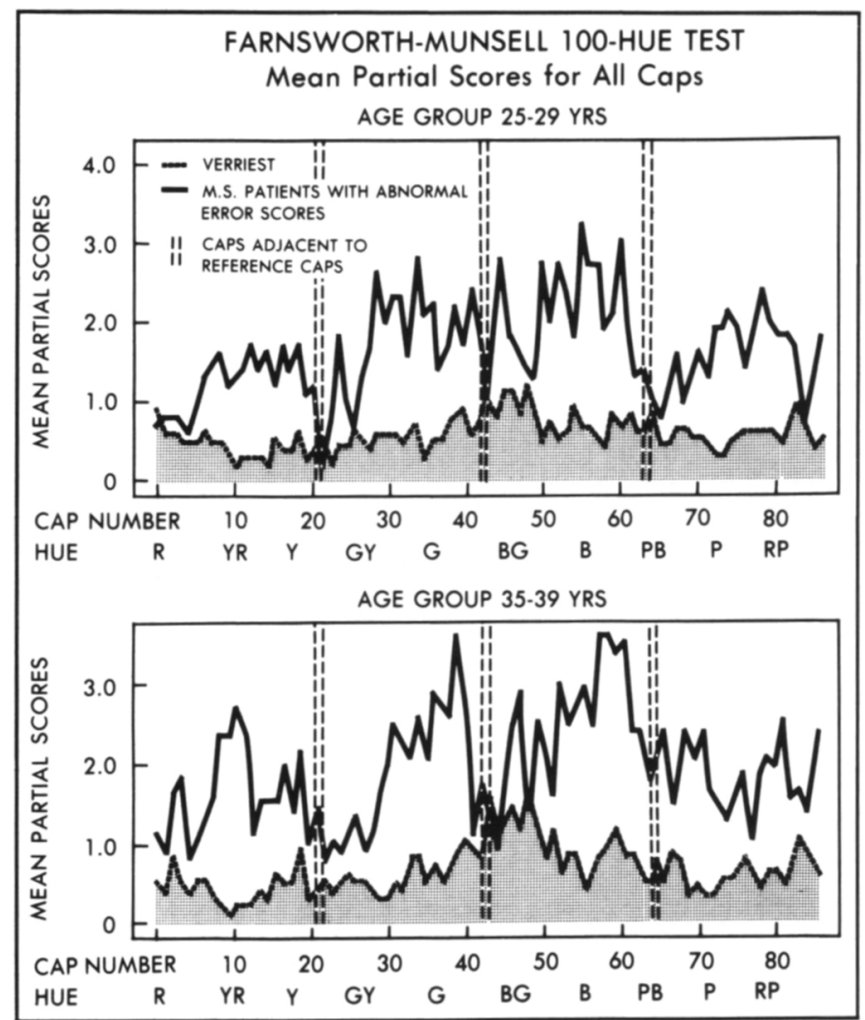

Figure $2-B y$ plotting the data for all $85 \mathrm{FM}-100$ Hue caps, the wavelength discrimination losses for M.S. patients with abnormal FM-100 Hue scores are very evident compared with the Verriest norms.

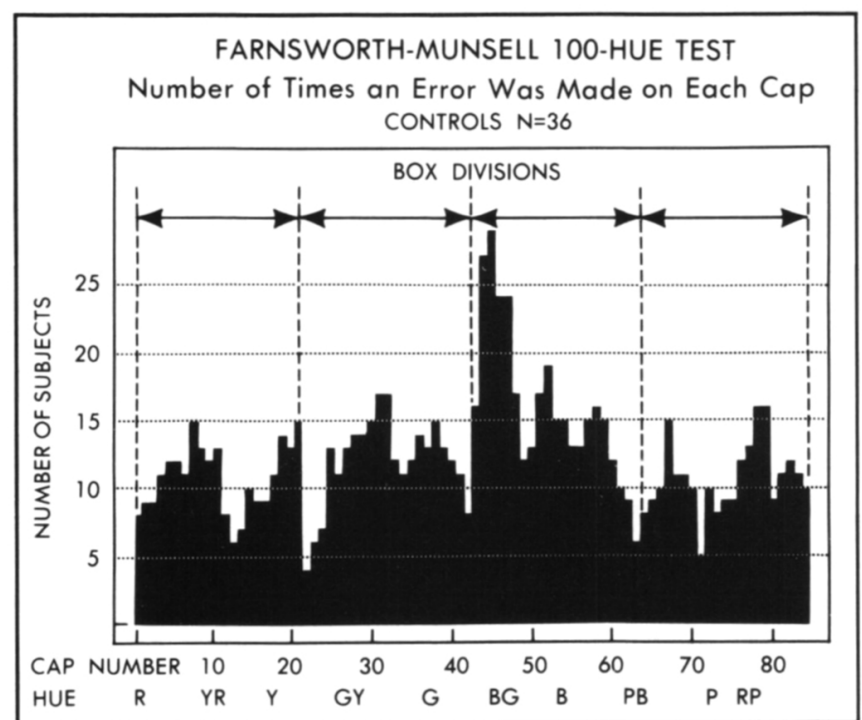

Figure 3 - There is a reduction in the number of errors made near the reference caps at each end of the four FM-100 Hue boxes.
End Effect" a frequency histogram was constructed for a control population with normal FM 100-Hue error scores (Figure 3 ). The number of subjects who made any errors was recorded for each of the caps. There was a noticeable reduction in the number of errors just before or just after each reference cap. Since it is in the blue-green spectral areas that M.S. patients had the most difficulty, the most artefact-free test for M.S. patients would be a double box, with caps 25 to 65 uninterrupted by reference caps.

\section{Colour Vision Deficit}

Although half of the patients tested (20 out of 40 ) reported AO-HRR plate number three incorrectly (one or both eyes), the majority of these subjects ( 17 of 20) also made errors on Ishihara plates and/or the FM 100-Hue test. The three subjects whose only demonstrable colour vision weakness was an abnormal response on one AO-HRR plate were not categorized as colour deficient. A colour deficit was assumed if:

1. A subject reported two or more of the first 16 lshihara plates incorrectly in one or both eyes ( $45 \%$ of patients, $11 \%$ of controls);

or

2. A subject had an abnormally high age-correlated error score in one or both eyes, on the FM 100 -Hue test $(42.5 \%$ of patients, $7 \%$ of controls).

By these criteria $65 \%$ of patients and $15 \%$ of controls demonstrated defective colour vision.

\section{Correlation of Test Results}

The data in Table 4 are provided to investigate the relationship between various indicators of visual function. The VEP findings for each eye were compared with the results of colour vision testing and the presence or absence of optic neuritis. The chi-square statistical test for evaluating independence between variables was performed. The null hypothesis was that the

Table 4: Visual Function Test Results (VEP Results Compared with Colour Vision Testing and Optic Neuritis)

\begin{tabular}{lclllll}
\hline & \multicolumn{2}{c}{ VEP } & & \multicolumn{2}{c}{ Chi Square } \\
\cline { 2 - 3 } & Normal & Abnormal & & & $\mathbf{X}^{2}$ & Significance \\
\hline Optic Neuritis & & & 35 & 17.07 & $\mathbf{p}<0.001$ \\
No (Normal) & 22 & 13 & 45 & & \\
Yes (Abnormal) & 8 & 37 & 50 & & &
\end{tabular}

lshihara

Normal

Abnormal

\begin{tabular}{rl}
22 & 30 \\
8 & 20 \\
\hline 30 & 50
\end{tabular}

FM 100-Hue

Normal

Abnormal

\begin{tabular}{rl}
23 & 30 \\
7 & 20 \\
\hline 30 & 50
\end{tabular}

Colour Vision

(Ishihara or

FM 100-Hue)

Normal

Abnormal

\begin{tabular}{ll}
17 & 19 \\
13 & 31 \\
\hline 30 & 50
\end{tabular}

36

2.64 $p>.1$ 
variables are independent. There was a statistically significant relationship between the findings with VEP testing and the presence of optic neuritis. In addition, the results of these two indicators of visual function correlated well. In $74 \%$ of eyes tested, the results of the two tests agreed, i.e., the eyes tested were either normal or abnormal on both tests. No statistically significant relationship was evident when the VEP results were compared with the results of colour vision testing.

If the results of both the Ishihara and the FM 100-Hue test are considered together, $16 \%(13 / 80)$ of eyes tested demonstrated colour vision deficits even though the VEP was normal. In $24 \%$ $(19 / 80)$ of eyes tested, there were abnormal VEP findings but normal colour vision. Therefore, the detection of visual system abnormalities is enhanced if both VEP results and colour vision tests are used.

Table 5 provides general information about patients based on their clinical diagnosis. Of the clinically definite patients (22/40), most had little or no physical disability $(73 \% \mathrm{~K} 0-\mathrm{K} 2)$; in one or both eyes tested there was a high proportion of probable (or history of) optic neuritis (86\%), VEP abnormalities (81\%), and colour vision defects $(73 \%)$. The early probable patients (7/40) were less affected, with all having $\mathrm{K} 0$ to $\mathrm{K} 2$ disability and a lower incidence of visual abnormalities (29\% optic neuritis, $43 \%$ abnormal VEP, $43 \%$ colour vision defects). The most severely affected were those patients classified as progressive probable. This group included the most severely disabled patients (86\% K5-K7) with a high incidence of visual disturbances (optic neuritis $86 \%$, VEP abnormalities $100 \%$, and colour vision defects $71 \%$ ).

The VEP results were the original criterion for patient selection. Patients with normal VEP's in both eyes ( $N=7$ patients), had the least frequent evidence of optic neuritis (17\% of patients) but, surprisingly, still had a significant proportion of colour vision defects $(57 \%)$.

\section{Discussion}

\section{Colour Vision Performance}

Colour vision losses were demonstrated in a significant proportion of M.S. patients: $42.5 \%$ of patients tested with the Farnsworth-Munsell 100-Hue test (FM 100-Hue test), 45\% tested with Ishihara Plates, and $65 \%$ if the results of both tests were considered.
Colour vision abnormalities occurred in patients with multiple sclerosis regardless of whether or not they had a past history or persistent evidence of optic neuritis. In our study, 44 of 80 eyes, in 28 of 40 patients, had optic atrophy or a history of optic neuritis. There was a positive statistical correlation between optic neuritis and abnormal delays in the visually evoked potentials. This finding agrees with the results of numerous other studies ${ }^{3,2.17}$ and, therefore, supports our diagnosis of optic neuritis. Although there was a highly significant positive correlation between a history of optic neuritis and an abnormal VEP, there was no such correlation between a history of optic neuritis and colour vision abnormalities. Some patients with optic neuritis demonstrated defects in colour vision. However, colour vision defects also occurred in patients without optic neuritis. In addition, the profile of colour vision disturbances evident on the FM 100-Hue test differed from that normally associated with optic neuritis. In this study, with the FM 100-Hue test, the defect presented as a generalized loss in colour discrimination, particularly in the blue area of the spectrum.

\section{Colour Vision Tests}

The colour vision tests used in this study differed in their clinical usefulness. The city university test was not very helpful since very few patients $(2.5 \%)$ and no controls made errors on the test. The panel D-15 was also somewhat insensitive (15\% errors in the patient group) and poor at distinguishing patients from controls (11\% errors in the control group). It might be possible to increase the sensitivity of the test using the Lanthony desaturated version which was designed for use with acquired colour vision disturbances. ${ }^{18}$ The AO-HRR was more sensitive and better at differentiating patients from controls. (Errors with $32.5 \%$ of eyes in $50 \%$ of patients and by $3.7 \%$ of eyes or subjects in the control population.) However, in half of those who failed the test an incorrect response on plate number 3 was the only error. We did not diagnose a patient as colour deficient on the basis of only one missed plate and would not recommend the $\mathrm{AO}-\mathrm{HRR}$ as the sole test for assessing colour vision performance. It would, however, be a useful addition to a battery of colour vision tests.

In this study, using the pass/fail criteria described in Results, the Ishihara test was quite useful in detecting disturbances of colour vision ( $31 \%$ of eyes; $45 \%$ of patients). However, further control studies are necessary to validate our pass/fail criteria.

Table 5: M.S. Patients According to Clinical Diagnosis Demonstrating the Amount of Physical Disability and Visual Impairment (VEP Delays, Colour Vision Defects or Optic Neuritis)

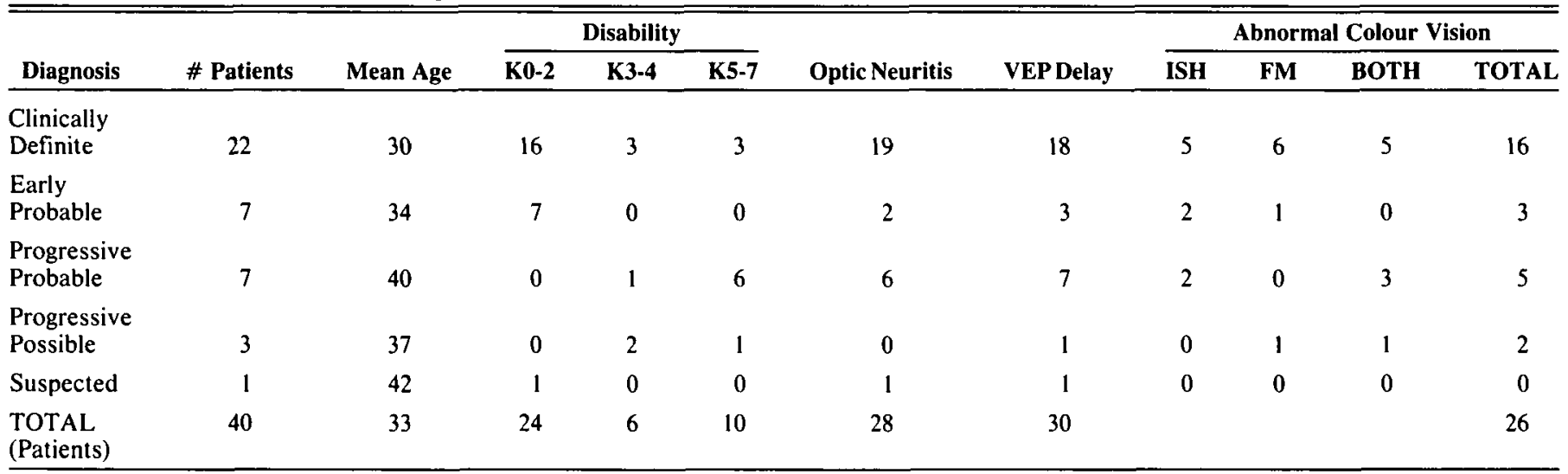


Although the Ishihara test may be useful in detecting colour vision anomalies it has two serious deficiencies: (1) there is no provision for assessing 'blue' deficits which we have found occur in M.S. patients and (2) since the defect cannot be reliably quantified, it is inappropriate for monitoring patients, particularly during therapy trials.

The F.M. 100-Hue is a full-spectrum hue-discrimination test which allows a comprehensive quantitative and qualitative assessment of colour vision disturbances. This provides a sound basis for monitoring a patient's visual function. However, before the test can be used to monitor the progress of patients on therapy, further studies are needed to determine colour vision performance with this test during the natural course of the disease. The Lanthony New Colour Test ${ }^{19}$ is another arrangement test, designed specifically for use in acquired colour vision defects. It allows determination of neutral zones (colours confused with grey) and evaluation of discriminative ability at each of four chroma (saturation) levels. This test was not used in our study but might be useful in future studies concerned with the clinical assessment of colour vision losses in M.S. patients.

There were distinct differences in performance on the battery of colour vision tests between subjects with known congenital colour vision deficiencies and M.S. patients. Subjects with congenital colour vision disturbances made a great many errors on the screening tests; in some instances all responses were incorrect. Errors occurred along a red-green axis of confusion on both the screening tests and on the FM 100-Hue test. On the FM 100-Hue test the total error scores were high but not excessively so, and in some cases the scores were even within normal age limits. In contrast, the profile of colour vision losses in M.S. patients was quite different. M.S. patients with colour vision losses tended to do well on the screening tests (with the exception of the Ishihara plates) but poorly on the FM 100-Hue test. In most cases the FM 100-Hue test error scores were clearly abnormal, with significant increases in total error scores. There were overall losses in wavelength discrimination particularly in the 'blue' area of the spectrum.

It is important to use more than one test to assess colour vision performance in M.S. patients. A battery of tests should include at least one screening test, to rule out a congenital disturbance, and a full-spectrum hue discrimination test such as the FM 100-Hue test to assess the severity and type of abnormality present. If the demonstration of a colour vision deficit is used (in conjunction with other findings) to confirm a diagnosis of M.S., the error score on the FM 100-Hue should be well above the norm expected for the age group. If the error score is on the border of normal limits, particularly in just one eye, the F.M. 100-Hue test should be repeated to confirm the colour defect. An additional investigation with an anomaloscope which allows a full-spectrum match would be extremely valuable although this is seldom possible in a clinical testing situation.

In summary, colour vision defects were present in a significant number of patients with multiple sclerosis, whether or not they had optic neuritis or visual evoked potential abnormalities. The defects presented as a generalized loss in wavelength discrimination, with some predilection for abnormalities in the "blue" area of the spectrum. These losses were the result of specific disturbances in hue discrimination by some patients rather than a generalized reduction in the discriminative abilities of all M.S. patients tested. There was a positive statistical correlation between a history or signs of optic neuritis and an abnormal VEP latency which supported the diagnosis of optic neuritis. However, there was no significant correlation between VEP results and colour vision test results. Since both tests uncover a significant number of clinically silent lesions, both are useful in the evaluation of patients with multiple sclerosis. The assessment of colour vision may be useful in the clinical evaluation of patients with multiple sclerosis, even if there is no evidence of optic neuritis or if other indicators of visual function (including visual evoked potentials) are normal.

\section{ACKNOWLEDGEMENT}

The investigation was supported in part by awards from the Alberta Heritage Foundation for Medical Research to A.C. Harrison and W.K. Stell. The assistance of the staff at the Clinical Neurophysiology Laboratory at the Calgary General Hospital, particularly Irene Richards and Betty Buswell, is gratefully acknowledged.

\section{REFERENCES}

1. Lumsden CE. In: Vinken PJ, Bruyn GW, eds. Handbook of Clinical Neurology, Vol. 9: Multiple Sclerosis and Other Demyelination Diseases. Amsterdam: North Holland Publishing Company. 1970: 234-237, 305-308.

2. Celesia GG. Visual evoked potentials in neurological disorders. Am J EEG Technol 1978; 18: 47-59.

3. Halliday AM, McDonald WI, Mushin J. Visually evoked potentials in patients with demyelinating disease. In: Desmedt TE, ed. Visually Evoked Potentials in Man: New Developments. Oxford: Clarendon Press, 1971: 438-449.

4. Regan DM. New visual tests in multiple sclerosis. In: Thompson HS, ed. Topics in Neuro-Ophthalmology. Baltimore: Williams and Wilkins, 1980: 219-242.

5. Harter MR, White CT. Effects of contour sharpness and check size on visually evoked cortical potentials. Vision Res 1968;8: 701-711.

6. Bodis-Wollner I, Hendley CD, Mylin LH, et al. Visual evoked potentials and the visogram in multiple sclerosis. Ann Neurol $1979 ; 5: 40-47$.

7. Griffin JF, Wray SH. Acquired colour vision defects in retrobulbar neuritis. Am J Ophthal 1978: 86: 193-201.

8. Wildberger VGH, van Lith GHM. Colour vision and visually evoked responses (VECP) in the recovery period of optic neuritis. Mod Prob Ophthal 1976; 17: 320-324.

9. Kirkham TH, Coupland SG. Multiple regression analysis of diagnostic predictors in optic nerve disease. Can J Neuro Sci 1981; 8: 67-72.

10. Rigolet MH, Mallecourt J, Leblanc M, et al. Étude de la vision des couleurs et des potentials evoques visuels dans le diagnostic de la sclerose en plaques. J Fr Ophthalmoi 1979; 10(2): 553-460.

11. Gouras and Zrenner. Colour vision: a review from a neurophysiological perspective. Progress in Sensory Physiology 1981; 1: 139-179.

12. McDonald WI, Halliday AM. Diagnosis and classification of multiple sclerosis. Br Med Bull 1977; 33: 4-8.

13. Kurtzke JF. Further notes on disability evaluation in multiple sclerosis, with scale modifications. Neurology $1965 ; 15: 654-661$.

14. Lakowski $R$. Is the deterioration of colour discrimination with age due to lens or retinal changes? Die Farbe 1962: 11: 69-86.

15. Farnsworth D. The Farnsworth-Munsell 100-Hue Test Manual (revised ed.) Baltimore: Munsell colour Company, 1957.

16. Verriest G. Further studies on acquired deficiency of colour discrimination. J Opt Soc Am 1963; 53: 185-195.

17. Asselman P, Chadwick DW, Marsden CD. Visual evoked responses in the diagnosis and management of patients suspected of multiple sclerosis. Brain 1975; 98: 261-282.

18. Lanthony P. The desaturated Panel D-15. Doc Ophthal 1978a; 46: 185-189.

19. Lanthony P. The new colour test. Doc Ophthal 1978b; 46: 191-199. 